\title{
Extinction, new learning and the unlearning phenomenon'
}

JOHN P. HOUSTON

UNIVERSITY OF CALIFORNIA, LOS ANGELES

Responses in an A-B, A-C retroactive inhibition situation were either from the same or from different classes of materials. The second task involved either the usual anticipation technique or a guessing method in which the $S$ did not experience consistent pairings of particular stimuli and responses. Significant unlearning appeared only when the second task involved the learning of similar materials. While the experiment is not conclusive it does suggest that both the unreinforced evocation of first-list responses and new learning may be necessary for the unlearning effect to appear.

There are at least two potential determinants of unlearning in the $\mathrm{A}-\mathrm{B}, \mathrm{A}-\mathrm{C}$ situation. On the one hand, unlearning of first-list associations may be the result of the evocation, either overt or covert, of first-list responses during second-list learning. Because they are not reinforced or confirmed during second-list acquisition, they are assumed to be weakened in a manner similar to that of experimental extinction. On the other hand, unlearning may be independent of the unreinforced evocation of first-list responses. According to this position the critical variable in the unlearning of old associations is the new learning which occurs during the second task.

Most of the studies investigating these variables have tried to hold second-list learning constant while varying first-list response evocation. These studies (Keppel \& Rauch, 1965; Postman, Keppel, \& Stark, 1965; Postman, 1965) lend some support to the extinction hypothesis but the importance of the new learning factor has not been established. The intent of the present study was to vary both factors simultaneously in a 2 by 2 RI design involving the A-B, A-C paradigm.

\section{Method}

Half the Ss (Same groups) were presented two successive paired-associate lists in which the stimuli were digits and the responses adjectives. The stimuli in the two lists presented to the remaining Ss (Different groups) were also digits but, in this case, the responses in the first list were adjectives and the second-list responses were bigrams. The assumption here is that overt and covert first-list response evocations will be most frequent when the response class remains the same. According to the extinction hypothesis unlearning will be greater in this instance. The second experimental manipulation was designed to vary amount of new learning while holding unreinforced evocation of first-list responses constant. One half of each of the Same and Different groups learned the second list by the usual PA anticipation method (Learn groups). The other halves were also given 16 trials involving the second list materials but, in this case, the stimuli and responses were re-paired on each succeeding trial. These Ss (Guess groups) were told, prior to the presentation of the second list, that the stimuli and responses would be repaired and that all they were required to do was to guess which response would occur each time a stimulus appeared. Thus learning, in the sense of the establishment of associations between stimuli and responses which consistently occur together, was minimized in this situation. On the other hand, the opportunity for firstlist responses to occur during presentation of the second list was maintained. The complete factorial design included four groups, Same-Learn, Different-Learn, Same-Guess, Different-Guess. A fifth group, a Control group, learned and recalled a single list. The Ss, run in an unsystematic order, were 80 University of California undergraduates. The stimuli in all lists were the digits 2 through 9. Two sets of eight two-syllable adjectives taken from the Barnes \& Underwood (1959) study were used as responses. One set served as responses in all first lists while the other served as responses in the Same condition second lists. The eight bigrams contained no vowels, and no letter was used more than once. Two pairings of the first-list stimuli and responses were used equally frequently in all conditions. Two pairings of the second-list stimuli and responses were used in the Learn conditions. Four presentation orders of these lists were used equally frequently as the starting point. In the Guess conditions the second-list stimuli and responses were randomly re-paired eight times and each $\mathrm{S}$ received all eight orders twice in succession. Each order was used equally frequently as the starting order. First-list learning was carried to a criterion of one perfect trial. All learning was at a $2: 2-\mathrm{sec}$, rate with a $4-\mathrm{sec}$. intertrial interval on a Stowe drum. One min. following second-list learning the stimuli were exposed one at a time in an S paced recall task.

\section{Results and Discussion}

Significant differences did not appear among the mean numbers of trials required by the five groups to reach criterion on the first-list, $F<1.0$. The mean numbers of correct responses given by the Same-Learn and Different-Learn groups during second-list learning were 96.06 and $83.19, \mathrm{t}=2.84, \mathrm{df}=30, \mathrm{p}<.01$. Although few correct responses were given by the DifferentGuess and Same-Guess groups, these Ss didacquire the new set of responses. The mean numbers of responses given from the correct second-list set by the Same- 
Guess and Different-Guess groups were 101.25 and 90.31.

Neither of the Different groups gave any first-list responses during second-list learning. Two interlist intrusions occurred in the Same-Guess condition and one in the Same-Learn condition. Although these frequencies are small they do agree with the supposition that more first-list response evocations will occur when the response class remains unchanged and with the assumption that the Guessing technique will result in at least as many evocations as the Learning technique.

The mean numbers of first-list responses recalled correctly by the Same-Learn, Different-Learn, SameGuess and Different-Guess groups were 3.19,6.69,7.06 and 7.69. Both the Learn-Guess, $\mathrm{F}=46.66, \mathrm{df}=1 / 60$, $p<.01$, and the Same-Different, $F=33.41, \mathrm{df}=1 / 60$, $\mathrm{p}<.01$, main effects were significant. More important, the interaction was significant, $F=16.23, \mathrm{df}=1 / 60$, $\mathrm{p}<.01$. The configuration of the data suggested that the significant interaction might be due to the extremely poor recall in the Same-Learn condition. Accordingly, each of the four experimental means was compared with the Control mean (7.56) by a method described in Winer (1962, p. 89). These comparisons indicated that significant unlearning occurred in the Same-Learn condition $(p<.01)$ but that none had appeared in any of the remaining conditions.

The principal finding of the experiment was that significant unlearning appeared only when the second task involved new learning of similar materials. No unlearning occurred when the types of responses were different or when the second-list Guessing technique was applied. These findings suggest that neither the evocation of first-list responses nor new learning are sufficient, but that both are necessary, for the unlearning phenomenon to appear.

of course there is the possibility that changing to a guessing task reduced first-list response evocation during second-list learning. If this were true then the lack of an unlearning effect in the Guessing condition could not be attributed to the importance of the new learning factor. Because of this possible confounding the results can only be suggestive.

\section{References}

Barnes, J. M., \& Underwood, B. J. "Fate" of first-list associations in transfer theory. J. exp. Psychol., 1959, 58, 97-105.

Keppel, G., \& Rauch, D. S. Unlearning as a function of second-list error instructions. J. verbal Learn. verbal Behav., 1966, 5, 50-58.

Postman, L. Unlearning under conditions of successive interpolation. J. exp. Psychol., 1965, 70, 237-245.

Postman, L., Keppel, G., \& Stark, K. Unlearning as a function of the relationship between successive responses classes. $J$. exp. Psychol., 1965, 69, 111-118.

Winer, B. J. Statistical principles in experimental design. New York: McGraw-Hill, 1962.

\section{Note}

1. This work was supported by a research grant (MH 11199-01 from the National Institute of Mental Health, Public Health Service.

\section{Erratum}

HOATS, D. L., \& GERJUOY, IRMA R. Associative symmetry with two conditions of perceptual organization. Psychon. Sci., 1966, 4 (10), 341-342.-Figure 1 was printed incorrectly. It should be rotated $90^{\circ}$ counter-clockwise. 